\title{
The Zandra Rhodes Digital Study Collection Project at the University for the Creative Arts
}

\author{
Amy Robinson \\ University for the Creative Arts \\ Falkner Road, \\ Farnham, GU9 7DS \\ arobinson@ucreative.ac.uk
}

\section{ABSTRACT}

This demonstration will enable participants to explore the extraordinary work of the British fashion and textile designer Zandra Rhodes. The Zandra Rhodes Digital Study Collection provides online access to a range of unseen dresses and garments from the designer's private archive. Participants will be given an opportunity to explore the archive as well as a range of supplementary resources created to support and enrich learning, teaching, and research.

The Zandra Rhodes Digital Study Collection project (November 2011 - February 2013) set out to digitally photograph, research, catalogue, and provide online access to 500 garments selected from the thousands held in the designer's London studio and apartment (UCA 2013a). This JISCfunded initiative was led by the University for the Creative Arts (UCA), a specialist art and design University with campuses across Kent and Surrey. Zandra Rhodes studied at one of UCA's founder colleges, the Medway College of Design, before pursuing a career in fashion spanning five decades, in which she has designed for clients such as Elizabeth Taylor, Freddie Mercury, and Diana, Princess of Wales. She became the University's first Chancellor in 2010.

A series of video tutorials were developed with the designer and her studio team demonstrating her production processes, as well video interviews revealing the inspiration behind her most iconic pieces and collections. 'Turning the Pages' technology was also used to provide access for the first time to her 'Style Bible' drawings comprehensively recording her designs.

This session will provide a range of insights into this unique collaboration with a living artist's archive, including: the opportunities for enriching the online archive with the personal knowledge, memories, and methods of its creator; the chance for students to see 'behind-the-scenes' in a working fashion studio on project internships; the dialogue around photographic objectivity, creativity and styling; the complexity of representing the three dimensionality of fashion and textiles; the engagement with academics and students and their user testing of the online resources; and an overview of legal considerations such as copyright and data protection.

The project was managed by UCA's Centre for Digital Scholarship, formerly the Visual Arts Data Service (VADS), ensuring that best practice was followed in terms of digital standards and preservation, and the project has subsequently been used as a case study for Research Data Management (RDM), as part of the Centre's Visual Arts Data Skills for Researchers (VADS4R) project workshop programme across UK creative arts institutions (UCA 2013b).

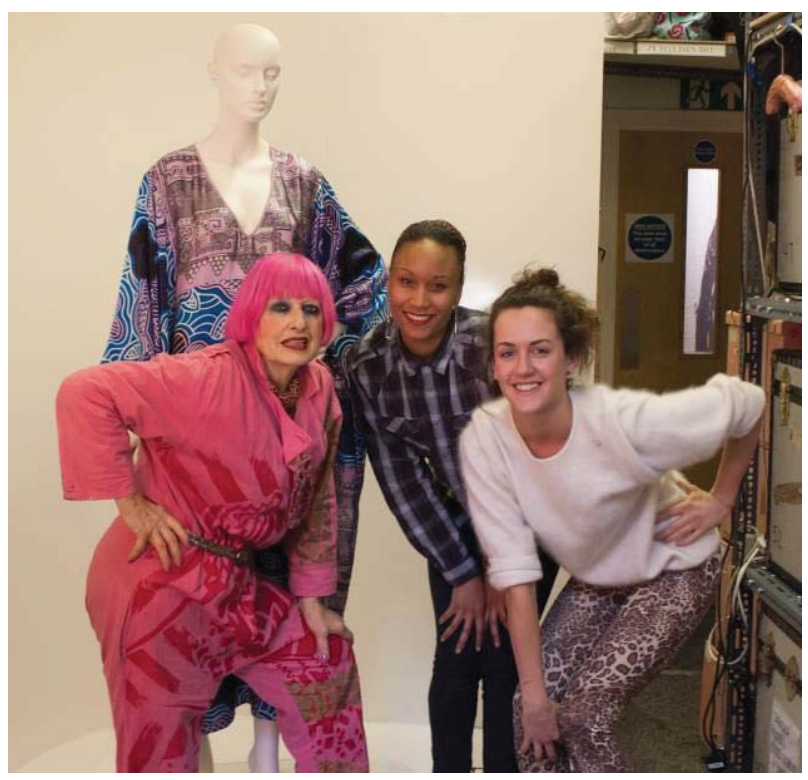

Figure 1: Zandra Rhodes with fashion design student interns from UCA 


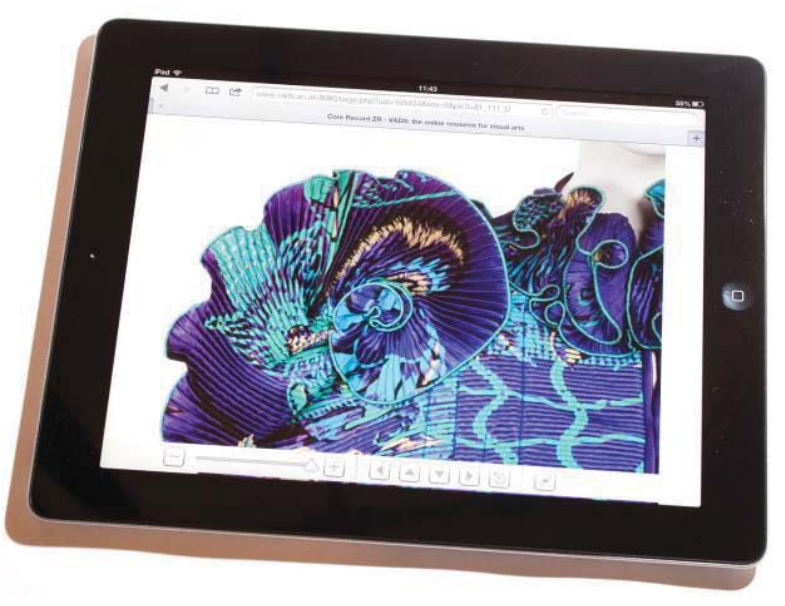

Figure 2: Jacket from The African Collection, 1981, by Zandra Rhodes @ Zandra Rhodes; viewed on a tablet computer

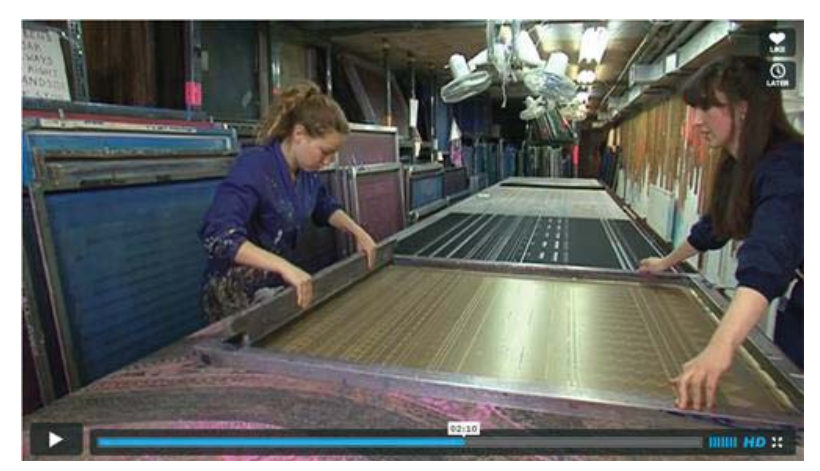

Figure 3: screen printing video tutorial with Caroline Carrig, Zandra Rhodes Studio, assisted by Adriana Jaroslavsky

\section{REFERENCES}

UCA (2013a) Zandra Rhodes Digital Study Collection.

http://www.zandrarhodes.ucreative.ac.uk (retrieved 23 December 2013).

UCA (2013b) Visual Arts Data Skills for Researchers (VADS4R) project. http://www.vads4r.vads.ac.uk (retrieved 23 December 2013). 